\author{
Dong Hwan Lee $\cdot$ Soo Kyung Koo $\cdot$ Kwang-Soo Lee \\ Young-Joo Yeon $\cdot$ Hyun-Jeong Oh $\cdot$ Sang-Wun Kim \\ Sook-Jin Lee · Sung-Soo Kim · Jong-Eun Lee \\ Inho Jo $\cdot$ Sung-Chul Jung
}

\title{
The molecular basis of phenylketonuria in Koreans
}

Received: 27 April 2004 / Accepted: 28 July 2004 / Published online: 16 October 2004

(C) The Japan Society of Human Genetics and Springer-Verlag 2004

\begin{abstract}
Phenylketonuria (PKU) is an inborn error of metabolism that results from a deficiency of phenylalanine hydroxylase $(\mathrm{PAH})$. We characterized the $P A H$ mutations of 79 independent Korean patients with PKU or hyperphenylalaninemia. $P A H$ nucleotide sequence analysis revealed 39 different mutations, including ten novel mutations. The novel mutations consisted of nine missense mutations (P69S, G103S, N207D, T278S, P281A, L293M, G332V, S391I, and A447P) and a novel splice site variant (IVS10-3C $>$ G). R243Q, IVS4-1G $>A$, and E6-96A $>\mathrm{G}$ were the most prevalent mutations, as they accounted for $32 \%$ of the total mutant alleles in this study. Although some common characteristics of allele frequency and distribution were identified among oriental populations, several distinctive characteristics were revealed in Korean patients. Although the $\mathrm{R} 413 \mathrm{P}$ allele is the most prevalent form $(30.5 \%)$ in Japanese, we detected it in only five chromosomes from 158 independent chromosomes (3.2\%). The A259T allele, which has not yet been found in oriental populations, was frequently found in this study. We also observed that tetrahydrobiopterin $\left(\mathrm{BH}_{4}\right)$ responsiveness was associated with specific genotypes
\end{abstract}

The first two authors contributed equally to this work.

D. H. Lee

Department of Pediatrics, School of Medicine,

Soonchunhyang University, Seoul, South Korea

S. K. Koo - K.-S. Lee $\cdot$ H.-J. Oh · S.-W. Kim - S.-J. Lee

S.-S. Kim $\cdot$ I. Jo $\cdot$ S.-C. Jung

Division of Genetic Disease,

Department of Biomedical Sciences,

National Institute of Health, 5 Nokbun-Dong,

Eunpyung-Gu, Seoul 122-701, South Korea

Y.-J. Yeon · J.-E. Lee

DNA Link, Inc., Seoul, South Korea

S.-C. Jung $(\square)$

Department of Biochemistry, College of Medicine,

Ewha Womans University, Seoul, South Korea

E-mail: jungsc@ewha.ac.kr

Tel.: + 82-2-26505724

Fax: + 82-2-26527846
(R53H, R241C, and R408Q), suggesting there are some correlations between phenotype and genotype.

Keywords Phenylketonuria $\cdot$ Phenylalanine

hydroxylase $\cdot$ Mutation $\cdot$ Allele $\cdot$ Frequency $\cdot$ Korean

\section{Introduction}

Phenylketonuria (PKU; MIM 261600) is an inborn error of metabolism inherited as an autosomal recessive trait. The incidences of PKU vary among ethnic populations: $1 / 10,000$ in Caucasian (Bickel et al. 1981), 1/120,000 in Japanese (Aoki and Wada 1988), and 1/18,000 in Chinese (Liu and Zuo 1986). In Korea, PKU incidence is estimated, from the neonatal screening that was introduced in 1998 , to be about $1 / 41,000$.

PKU results from a deficiency of phenylalanine hydroxylase (PAH). The $P A H$ gene spans about $90 \mathrm{~kb}$ on chromosome $12 \mathrm{q}$ and comprises 13 exons. PAH is a hepatic enzyme that catalyzes hydroxylation of phenylalanine to tyrosine using tetrahydrobiopterin $\left(\mathrm{BH}_{4}\right)$ as a cofactor. It has three structural domains consisting of an $\mathrm{N}$-terminal regulatory domain, a catalytic domain, and a C-terminal tetramerization domain. The active PAH enzyme is comprised of four monomeric proteins. Recent studies of PAH crystal structure have provided information on the active site and the binding sites of its substrate and cofactor.

The mutation profile of the $P A H$ gene is not restricted to any one region but spreads throughout the entire structural domains and shows enormous diversity. More than 460 different mutations of the $P A H$ gene have been identified and recorded in the PAH Mutation Analysis Consortium Database (PAHdb; Scriver et al. 2003). The severity of the disease is also diverse from mild hyperphenylalaninemia (MHP) to classical PKU, which is characterized by pretreatment blood phenylalanine levels or dietary tolerance (Guldberg et al. 1998). Another phenotypic characteristic is $\mathrm{BH}_{4}$ responsive- 
ness. The serum phenylalanine levels of $\mathrm{BH}_{4}$-responsive patients are controlled by $\mathrm{BH}_{4}$ oral administration without phenylalanine restriction diet. Several studies have investigated the relationship between genotype and this diverse phenotypic expression. Determining the relationship between genotype and phenotype would provide very useful information for planning dietary and therapeutic strategies.

Therefore, we analyzed the $P A H$ gene in 79 patients with PKU and their families to study genotype-phenotype relationships and to help with genetic counseling. Furthermore, we analyzed the mutation spectra of the $P A H$ gene in Korean patients and compared them with those of other ethnic groups, including Japanese and Chinese.

\section{Subjects and methods}

\section{Subjects}

This study was approved by the institutional review board of the National Institute of Health, Korea. The study included 79 unrelated families with PAH deficiency. Participants were recruited from the Korean PKU family support group. Most of them were identified in neonatal screening, and PAH deficiency was diagnosed by conventional biochemical methods. Patient severity was assigned to classical PKU, moderate PKU, or MHP, according to the plasma phenylalanine concentration prior to phenylalanine restriction diet. The level for classical PKU was $1,200 \mu \mathrm{M}$ or more; the level for moderate PKU $600-1,200 \mu \mathrm{M}$; the level for MHP less than $600 \mu \mathrm{M}$. Informed consent for DNA analysis was obtained from the patients and their families.

For the $\mathrm{BH}_{4}$ loading test, patients without a phenylalanine restriction diet were administered orally at a dose of $20 \mathrm{mg} / \mathrm{kg}$ (for the patients under 36 months old) or $7.5 \mathrm{mg} / \mathrm{kg}$ (for the patients over 36 months old). Blood phenylalanine levels were measured before, 1, 2, 4, 6, 8, 12 , and $24 \mathrm{~h}$ after administration. The $\mathrm{BH}_{4}$ loading test was considered positive when initial plasma phenylalanine concentration decreased by at least $40 \%$ after $12 \mathrm{~h}$. Urinary pterin analysis and dihydropteridine reductase (DHPR) assay were performed to exclude 6-pyruvoyltetrahydropterin synthase (PTPS) deficiencies.

\section{Mutation analysis}

Genomic DNA was isolated from peripheral blood leukocytes using the QIAamp DNA blood kit following the manufacturer's instruction (Qiagen, Hilden, Germany). All 13 exons including exon-intron boundaries and $2 \mathrm{~kb}$ of the $5^{\prime}$-upstream region of the $P A H$ gene were amplified by PCR. PCR amplicons were extracted from an agarose gel using a gel extraction kit (Qiagen). Direct sequencing was performed using a BigDye
Terminator Cycle Sequencing Ready Reaction Kit, version 2.0 (PE Applied Biosystems, Foster City, CA, USA) and analyzed with an ABI 3100 automated sequencer (PE Applied Biosystems) according to the standard methods. When available, parental DNA samples were sequenced to confirm trans configurations in compound heterozygotes and to distinguish homozygosity from hemizygosity. In addition, $P A H$ genes in 50 normal individuals were analyzed to confirm that the novel sequence variations were not polymorphisms but real pathogenic mutations. Novel mutations were defined by exclusion from the PAHdb (http://www.pahdb.mcgill.ca) and previously reported mutations on PubMed (http://www.ncbi.nlm.nih.gov/PubMed/).

\section{Results and discussion}

$P A H$ nucleotide sequence analysis of 79 unrelated PKU probands revealed 39 different mutations (Tables 1, 2). Among 79 patients, two mutation alleles were detected in 59 patients $(75 \%)$, either compound heterozygous or homozygous (52 and seven, respectively). Only one mutation allele was revealed in 19 patients, and no mutations were detected in two patients. Ten novel mutations were identified in this study. These novel mutations included nine missense substitutions: P69S, G103S, N207D, T278S, P281A, L293M, G332V, S391I, and A447P. From database comparison, the glycine ${ }^{103}$ is found to be conserved among human, mouse, and rat. The remaining mutated amino acid residues were even more strictly conserved among human, mouse, rat, and zebrafish. A novel splice-site variant, IVS10-3C $>\mathrm{G}$, was also detected. The -3 sequence of the splicing acceptor site is a strictly conserved sequence, and this substitution might result in aberrant splicing products. No novel frameshift mutations or nonsense mutations were detected.

R243Q, IVS4-1G $>A$, and E6-96A $>G$ were the most prevalent mutations in Korean patients with PKU. They have been reported to be some of the most frequent mutations in Asian populations (Table 3) and accounted for 51 of the 158 total chromosomes $(32.2 \%)$ in this study.

It is well known that different ethnic groups have their own distinctive and diverse $P A H$ mutant allele series that include one or a few prevalent founder alleles (Zschocke 2003). In comparison of $P A H$ mutation data among ethnic groups, there are the correlations between mutation and genetic history of investigated populations. For example, in Europe, there are several prevalent founder alleles, including $\mathrm{R} 408 \mathrm{~W}$, IVS12 $+1 \mathrm{G}>\mathrm{A}$, IVS10-11G $>\mathrm{A}$, and $\mathrm{Y} 414 \mathrm{C}$, that represent the expansion, migration, and genetic drift of European populations (Zschocke 2003). In particular, the R408W mutation has a frequency of $20-84 \%$ in PKU patients in Eastern Europe and Germany. However, these mutations are rarely detected in oriental populations. In a previous study, Okano et al. (1992) 
Table 1 Genotypes for mutations of the $P A H$ gene in 79 Korean phenylketonuria (PKU) patients

\begin{tabular}{|c|c|c|c|}
\hline Patient number & $P A H$ allele 1 & $P A H$ allele 2 & Class $^{\mathrm{b}}$ \\
\hline 1 & IVS4-1G $>A$ & A259T & Classical \\
\hline 2 & $\mathrm{P} 407 \mathrm{~S}$ & R413P & Moderate \\
\hline $3^{\mathrm{a}}$ & Y356X & R408Q & Moderate \\
\hline 4 & S70[del] & $\mathrm{L} 255 \mathrm{~S}$ & MHP \\
\hline 5 & N207D & Y325X & Classical \\
\hline 6 & Y204C & ? & Classical \\
\hline 7 & Y204C & ? & NA \\
\hline 8 & Y356X & $?$ & Classical \\
\hline 9 & IVS4-1G >A & R243Q & Classical \\
\hline $10^{\mathrm{a}}$ & R241C & $\mathrm{T} 278 \mathrm{I}$ & Moderate \\
\hline 11 & R243Q & ? & NA \\
\hline 12 & R243Q & $?$ & NA \\
\hline 13 & A259T & $\mathrm{T} 278 \mathrm{I}$ & NA \\
\hline 14 & A345T & G332V & Classical \\
\hline 15 & G103S & R413P & NA \\
\hline 16 & IVS4-1G $>A$ & V388M & NA \\
\hline 17 & R243Q & R252Q & NA \\
\hline 18 & A259T & $?$ & NA \\
\hline 19 & R413P & Y325X & NA \\
\hline 20 & IVS2nt $-2 \mathrm{~T}>\mathrm{C}$ & $?$ & Moderate \\
\hline 21 & Y204C & Y204C & NA \\
\hline 22 & Y325X & V388M & Classical \\
\hline 23 & Y204C & $?$ & Classical \\
\hline 24 & IVS4-1G $>A$ & V388M & NA \\
\hline 25 & $\mathrm{R} 241 \mathrm{C}$ & $\mathrm{R} 241 \mathrm{C}$ & MHP \\
\hline $26^{\mathrm{a}}$ & $\mathrm{R} 53 \mathrm{H}$ & R243Q & Moderate \\
\hline 27 & N207D & ? & NA \\
\hline 28 & Y204C & Y204C & Classical \\
\hline 29 & R111X & R243Q & NA \\
\hline 30 & A259T & $?$ & NA \\
\hline 31 & $\mathrm{R} 176 \mathrm{X}$ & A259T & NA \\
\hline 32 & IVS4-1G $>A$ & $?$ & Classical \\
\hline 33 & Y204C & Y356X & Classical \\
\hline 34 & R158Q & R243Q & NA \\
\hline 35 & IVS4-1G $>A$ & L293M & Classical \\
\hline 36 & IVS4-1G >A & Y356X & NA \\
\hline 37 & R243Q & P281A & Classical \\
\hline 38 & $\mathrm{D} 84 \mathrm{Y}$ & Y356X & NA \\
\hline $39^{\mathrm{a}}$ & $\mathrm{R} 241 \mathrm{C}$ & R243Q & Moderate \\
\hline 40 & Y204C & ? & Classical \\
\hline 41 & R243Q & V388M & Classical \\
\hline 42 & P69S & R261Q & NA \\
\hline 43 & S70[del] & IVS4-1G > A & Classical \\
\hline 44 & IVS4-1G > A & $?$ & Classical \\
\hline 45 & R413P & ? & Classical \\
\hline 46 & Y204C & ? & NA \\
\hline 47 & W187X & Y356X & Classical \\
\hline 48 & IVS4-1G $>A$ & R243Q & NA \\
\hline 49 & R243Q & ? & Moderate \\
\hline $50^{\mathrm{a}}$ & R241C & A259T & Moderate \\
\hline 51 & IVS4-1G $>A$ & S310F & Moderate \\
\hline 52 & Y204C & Y $325 X$ & MHP \\
\hline 53 & R243Q & A $345 \mathrm{~T}$ & NA \\
\hline 54 & IVS4-1G $>A$ & $\mathrm{~T} 278 \mathrm{~S}$ & Classical \\
\hline 55 & $\mathrm{~T} 278 \mathrm{I}$ & R413P & NA \\
\hline 56 & G332E & ? & NA \\
\hline 57 & A259T & ? & NA \\
\hline 58 & T278I & Y356X & Classical \\
\hline 59 & Y204C & R243Q & NA \\
\hline $60^{\mathrm{a}}$ & $\mathrm{R} 241 \mathrm{C}$ & A259T & Moderate \\
\hline 61 & IVS10-3C > G & IVS10-3C $>G$ & NA \\
\hline 62 & Y204C & P281L & NA \\
\hline 63 & $\mathrm{R} 53 \mathrm{H}$ & V388M & MHP \\
\hline 64 & A447P & $?$ & NA \\
\hline 65 & R243Q & A345T & Classical \\
\hline 66 & R176X & S391I & Classical \\
\hline
\end{tabular}

Table 1 (Continued)

\begin{tabular}{llll}
\hline Patient number & $P A H$ allele 1 & $P A H$ allele 2 & Class $^{\mathrm{b}}$ \\
\hline 67 & IVS4-1G $>$ A & R261X & NA \\
$68^{\mathrm{a}}$ & R241C & R243Q & Moderate \\
69 & IVS4-1G $>$ A & IVS4-1G $>$ A & Classical \\
70 & R243Q & Y325X & NA \\
71 & Y356X & $?$ & NA \\
72 & IVS4-1G $>$ A & P281L & Moderate \\
73 & G239S & P281L & Classical \\
74 & R243Q & Y356X & NA \\
75 & Y204C & Y204C & Classical \\
76 & R241C & R241C & MHP \\
77 & A259T & T278I & NA \\
78 & Y204C & R243Q & NA \\
79 & $?$ & $?$ & NA \\
\hline${ }^{a} \mathrm{BH}_{4}$ responsive type & & \\
${ }^{\mathrm{b}}$ NA not available & &
\end{tabular}

reported the frequency and distribution of $P A H$ gene mutations among Japanese, Korean, and Chinese patients. Because the study was undertaken in the early 1990s, it was restricted to screening for previously isolated mutations. Unidentified but relatively frequent alleles, such as R241C, were not investigated, and only ten Korean patients were included, which is a relatively small number to represent Korean allelic distribution. The present study, with 79 participants, extends these previous results to give a more comprehensive understanding of $P A H$ allele distribution and frequency in Koreans. Although some overlaps of mutant allele distribution are observed among Japanese, Chinese, and Korean populations, there are several significant differences (Table 3). R243Q, E6-96A $>$ G, and IVS4-1G $>A$, the most frequent mutations in our study, are also frequently detected in Japanese, Chinese, and Taiwanese. However, R111X, a frequent mutation in Japanese and Chinese patients, is very rare in Korean patients. R413P is the most prevalent allele in Japanese, but a very small proportion of probands have the R413P allele in Korean and Taiwanese. IVS4-1G $>$ A occupied a relatively larger proportion in Korean mutant allele profiles than in Japanese or Chinese. Although A259T was not detected in any other oriental population studies, it was identified in nine different families in this study.

Interestingly, the two R241C homozygous patients (patient 25 and patient 76) showed MHP, and all compound heterozygous individuals with R241C (2 with R241C/R243Q, another 2 with R241C/A259T and 1 with $\mathrm{R} 241 \mathrm{C} / \mathrm{T} 278 \mathrm{I}$ ) showed $\mathrm{BH}_{4}$ responsiveness (Table 1, Fig. 1). In a previous study, PAH with R241C substitution showed to have $25 \%$ of residual activity in the COS cell expression system (Okano et al. 1994). Guldberg et al. (1998) assigned the patient with a R241C genotype to the MHP category. It was also reported that the blood phenylalanine levels of R241C/R413P patients was decreased by oral administration of $\mathrm{BH}_{4}$ (Kure et al. 1999). R241 is located near the cofactor binding region and does not directly interact with the cofactor, so the 
Table 2 Spectrum of $P A H$ mutations detected in this study a (1) Mutations reported in the PAHdb, (2) mutation reported by Song et al. (2003), (3) mutation reported by Chien et al. (2004), (4) mutation reported by Park et al. (1998)

\begin{tabular}{|c|c|c|c|c|c|c|}
\hline Mutation name & Normal & Mutation & Location & $\begin{array}{l}\text { Allele } \\
\text { frequency }\end{array}$ & $\begin{array}{l}\text { Relative } \\
\text { frequency }(\%)\end{array}$ & References $^{\mathrm{a}}$ \\
\hline $\mathrm{R} 53 \mathrm{H}$ & CGC & $\mathrm{CAC}$ & Exon 2 & 2 & 1.3 & 1 \\
\hline IVS2-2T >C & & & Intron 2 & 1 & 0.6 & 2 \\
\hline P69S & CCT & TCT & Exon 3 & 1 & 0.6 & Novel \\
\hline S70[del] & $\mathrm{TCT}$ & $\begin{array}{l}\text { c. } 208-210 \\
\text { delTCT }\end{array}$ & Exon 3 & 2 & 1.3 & 1 \\
\hline D84Y & GAT & TAT & Exon 3 & 1 & 0.6 & 1 \\
\hline G103S & GGT & AGT & Exon 3 & 1 & 0.6 & Novel \\
\hline $\mathrm{R} 111 \mathrm{X}$ & CGA & TGA & Exon 3 & 1 & 0.6 & 1 \\
\hline IVS4-1G $>A$ & GT & $\mathrm{AT}$ & Intron 4 & 16 & 10.1 & 1 \\
\hline R158Q & CGG & CAG & Exon 5 & 1 & 0.6 & 1 \\
\hline R176X & CGA & TGA & Exon 6 & 2 & 1.3 & 1 \\
\hline W187X & TGG & TAG & Exon 6 & 1 & 0.6 & 1 \\
\hline E6-96A $>G$ & & & Exon 6 & 16 & 10.1 & 1 \\
\hline N207D & AAT & GAT & Exon 6 & 2 & 1.3 & Novel \\
\hline G239S & GGT & AGT & Exon 7 & 1 & 0.6 & 1 \\
\hline $\mathrm{R} 241 \mathrm{C}$ & $\mathrm{CGC}$ & TGC & Exon 7 & 9 & 5.7 & 1 \\
\hline R243Q & CGA & CAA & Exon 7 & 19 & 12.0 & 1 \\
\hline $\mathrm{R} 252 \mathrm{Q}$ & CGG & $\mathrm{CAG}$ & Exon 7 & 1 & 0.6 & 3 \\
\hline L255S & TTG & $\mathrm{TCG}$ & Exon 7 & 1 & 0.6 & 1 \\
\hline A259T & GCC & $\mathrm{ACC}$ & Exon 7 & 9 & 5.7 & 1 \\
\hline R261Q & CGA & CAA & Exon 7 & 1 & 0.6 & 1 \\
\hline R261X & CGA & TGA & Exon 7 & 1 & 0.6 & 1 \\
\hline T278I & ACC & ATC & Exon 7 & 5 & 3.2 & 1 \\
\hline T278S & $\mathrm{ACC}$ & $\mathrm{AGC}$ & Exon 7 & 1 & 0.6 & Novel \\
\hline P281L & CCT & CTT & Exon 7 & 3 & 1.9 & 1 \\
\hline P281A & CCT & GCT & Exon 7 & 1 & 0.6 & Novel \\
\hline L293M & TTG & ATG & Exon 8 & 1 & 0.6 & Novel \\
\hline S310F & $\mathrm{TCT}$ & TTT & Exon 9 & 1 & 0.6 & 1 \\
\hline $\mathrm{Y} 325 \mathrm{X}$ & TAC & TAG & Exon 10 & 5 & 3.2 & 4 \\
\hline G332E & GGG & GAG & Exon 10 & 1 & 0.6 & 1 \\
\hline G332V & GGG & GTG & Exon 10 & 1 & 0.6 & Novel \\
\hline A345T & GCT & ACT & Exon 10 & 3 & 1.9 & 1 \\
\hline IVS10-3C > G & & & Intron 10 & 2 & 1.3 & Novel \\
\hline Y356X & TAC & TAA & Exon 11 & 9 & 5.7 & 1 \\
\hline V388M & GTG & ATG & Exon 11 & 5 & 3.2 & 1 \\
\hline S391I & AGT & ATT & Exon 11 & 1 & 0.6 & Novel \\
\hline $\mathrm{P} 407 \mathrm{~S}$ & CCT & $\mathrm{TCT}$ & Exon 12 & 1 & 0.6 & 1 \\
\hline R408Q & CGG & CAG & Exon 12 & 1 & 0.6 & 1 \\
\hline R413P & CGC & $\mathrm{CCC}$ & Exon 12 & 5 & 3.2 & 1 \\
\hline A447P & GCC & $\mathrm{CCC}$ & Exon 13 & 1 & 0.6 & Novel \\
\hline Total & & & & 136 & 86 & \\
\hline
\end{tabular}

Table 3 Relative frequencies of common $P A H$ gene mutation found in oriental populations

\begin{tabular}{lcccc}
\hline Mutation & \multicolumn{3}{l}{ Relative frequencies $(\%$, allele frequency/total subject chromosome) } \\
\cline { 2 - 5 } & 79 Korean & $\begin{array}{l}\text { 41 Japanese } \\
\text { (Okano et al. 1998) }\end{array}$ & $\begin{array}{l}\text { 52 Chinese } \\
\text { (Okano et al. 1992) }\end{array}$ & $\begin{array}{l}\text { 25 Taiwanese } \\
\text { (Chien et al. 2004) }\end{array}$ \\
\hline R243Q & 12.0 & 7.3 & 18.3 & 6 \\
IVS4-1G/A & 10.1 & 7.3 & 7.7 & 2 \\
E6-96A $>$ G & 10.1 & 6.1 & 11.5 & 4 \\
R241C & 5.7 & 7.3 & NA & 32 \\
A259T & 5.7 & 0 & NA & 0 \\
Y356X & 5.7 & 4.9 & 6.7 & 0 \\
T278I & 3.2 & 7.3 & NA & 0 \\
Y325X & 3.2 & 0 & NA & 0 \\
V388M & 3.2 & 1.2 & NA & 4 \\
R413P & 3.2 & 30.5 & 8.7 & 4 \\
R111X & 0.6 & 3.7 & 10.7 & 14 \\
R408Q & 0.6 & 0 & NA & 90.0 \\
Total detected & 86.0 & 92.7 & 66.5 & 4 \\
\end{tabular}

${ }^{\mathrm{a}} N A$ not available

Patient 3 (genotyped with Y356X/R408Q) also represented $\mathrm{BH}_{4}$ responsiveness. Y356X is a null mutation and may not be the $\mathrm{BH}_{4}$-responsive allele. $\mathrm{R} 408 \mathrm{Q}$ was mutation may lead to relatively mild structural deformities (Erlandsen and Stevens 2001). Our data are consistent with these previous reports. 


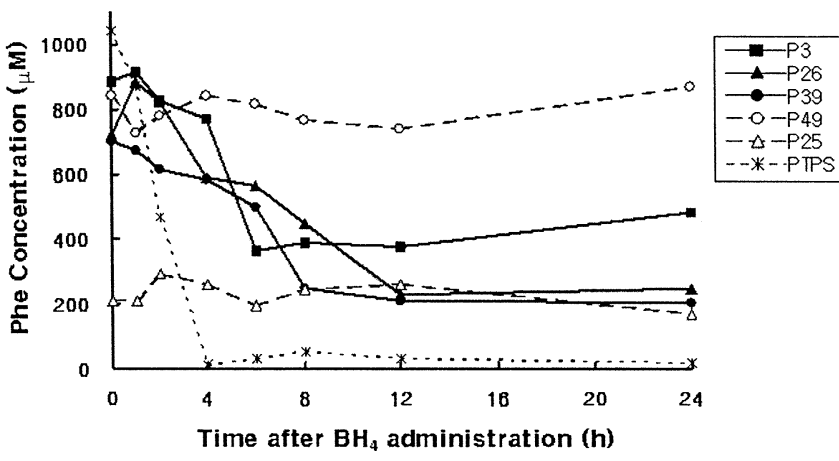

Fig. 1 Profile of blood phenylalanine concentration changes during the $\mathrm{BH}_{4}$ loading test. Filled square, patient 3 with $\mathrm{Y} 356 \mathrm{X} / \mathrm{R} 408 \mathrm{Q}$ genotype; filled triangle, patient 26 with $\mathrm{R} 53 \mathrm{H} / \mathrm{R} 243 \mathrm{Q}$; and filled circle, patient 39 with $\mathrm{R} 241 \mathrm{C} / \mathrm{R} 243 \mathrm{Q}$ showed the $\mathrm{BH}_{4}$ responsive pattern; and open triangle, patient 25 with R241C/R241C; and open circle, patient 49 with $\mathrm{R} 243 \mathrm{Q} /$ ? showed the nonresponsive pattern

reported to be associated with near-normal levels of residual activity in eukaryotic and prokaryotic expression system (Pey et al. 2003). The residual activity of $\mathrm{R} 408 \mathrm{Q}$ and the $\mathrm{BH}_{4}$ responsiveness of patient 3 indicate that $\mathrm{R} 408 \mathrm{Q}$ is one of the $\mathrm{BH}_{4}$-responsive alleles.

Our data added $\mathrm{R} 53 \mathrm{H}$ to the list of $\mathrm{BH}_{4}$-responsive PAH alleles. Patient 26 (genotyped with R53H/R243Q) represented $\mathrm{BH}_{4}$ responsiveness. The facts that $\mathrm{R} 243 \mathrm{Q}$ was associated with classical PKU in our study and another R53H heterozygous patient was MHP suggested that $\mathrm{R} 53 \mathrm{H}$ had some residual enzyme activity and brought out the responsiveness in patient 26 .

The $\mathrm{BH}_{4}$ response pattern between the PTPS-deficient patient and the PKU patient are somewhat different (Fig. 1). Phenylalanine levels of the PTPS patient was dramatically and completely decreased to the normal level after administration of $\mathrm{BH}_{4}$; in the $\mathrm{PKU}$ patient, the decrease was relatively retarded, and the blood phenylalanine concentration remained at the higherthan-normal level. The basal phenylalanine level of patient 25 (R241C homozygote) was too low to represent $\mathrm{BH}_{4}$ responsiveness.

In the $\mathrm{BH}_{4}$-non-responsive patients, the phenylalanine level remained at the same level as the starting point (Fig. 1). Some moderate PKU patients (patient 49 and 72) did not respond to the $\mathrm{BH}_{4}$. This result suggests that $\mathrm{BH}_{4}$ responsiveness requires some residual enzyme activity, but all the cases with mild phenotype are not associated with the $\mathrm{BH}_{4}$ responsiveness.

In summary, we screened the $P A H$ gene in 79 Korean PKU-affected families and identified 39 mutations, including ten novel mutations. Although the Korean mutation profile of $P A H$ is similar to those of the nearest oriental populations, there are several different characteristic features. The relationship of genotype and phenotype, especially $\mathrm{BH}_{4}$ responsiveness of some patients, was also described. This study would contribute to the diagnosis, genetic counseling, and planning of the dietary and therapeutic strategy in PKU patients.

Acknowledgements The authors thank the members of the Korean PKU family support group for their contribution and cooperation in this research. This study was supported by an intramural research fund from the National Institute of Health, Korea.

\section{References}

Aoki K, Wada Y (1988) Outcome of the patients detected by newborn screening in Japan. Acta Paediatr Jpn 30:429-434

Bickel H, Bachmann C, Beckers R, Brandt NJ, Clayton BE, Corrado G, Feingold HJ, Giardini O, Hammersen G, Schonberg D (1981) Neonatal mass screening for metabolic disorders. Eur J Pediatr 137:133-139

Chien YH, Chiang SC, Huang A, Chou SP, Tseng SS, Huang YT, Hwu WL (2004) Mutation spectrum in Taiwanese patients with phenylalanine hydroxylase deficiency and a founder effect for the R241C mutation. Hum Mutat 23:206

Erlandsen H, Stevens RC (2001) A structural hypothesis for BH4 responsiveness in patients with mild forms of hyperphenylalaninaemia and phenylketonuria. J Inherit Metab Dis 24:213230

Guldberg P, Rey F, Zschocke J, Romano V, Francois B, Michiels L, Ullrich K, Hoffmann GF, Burgard P, Schmidt H, Meli C, Riva E, Dianzani I, Ponzone A, Rey J, Guttler F (1998) A European multicenter study of phenylalanine hydroxylase deficiency: classification of 105 mutations and a general system for genotype-based prediction of metabolic phenotype. Am J Hum Genet 63:71-79

Kure S, Hou DC, Ohura T, Iwamoto H, Suzuki S, Sugiyama N, Sakamoto O, Fujii K, Matsubara Y, Narisawa K (1999) Tetrahydrobiopterin-responsive phenylalanine hydroxylase deficiency. J Pediatr 135:375-378

Liu SR, Zuo QH (1986) Newborn screening for phenylketonuria in eleven districts. Chin Med J (Engl) 99:113-118

Okano Y, Hase Y, Lee D-H, Furuyama JI, Shintaku H, Oura T, Isshiki G (1992) Frequency and distribution of phenylketonuric mutations in Orientals. Hum Mutat 1:216-220

Okano Y, Hase Y, Lee DH, Takada G, Shigematsu Y, Oura T, Isshiki G (1994) Molecular and population genetics of phenylketonuria in Orientals: correlation between phenotype and genotype. J Inherit Metab Dis 17:156-159

Okano Y, Asada M, Kang Y, Nishi Y, Hase Y, Oura T, Isshiki G (1998) Molecular characterization of phenylketonuria in Japanese patients. Hum Genet 103:613-618

Park YS, Seoung CS, Lee SW, Oh KH, Lee DH, Yim J (1998) Identification of three novel mutations in Korean phenylketonuria patients: R53H, N207D, and Y325X. Hum Mutat Suppl 1:S121-S122

Pey AL, Desviat LR, Gamez A, Ugarte M, Perez B (2003) Phenylketonuria: genotype-phenotype correlations based on expression analysis of structural and functional mutations in PAH. Hum Mutat 21:370-378

Scriver CR, Hurtubise M, Konecki D, Phommarinh M, Prevost L, Erlandsen H, Stevens R, Waters PJ, Ryan S, McDonald D, Sarkissian C (2003) PAHdb 2003: what a locus-specific knowledgebase can do? Hum Mutat 21:333-344

Song F, Jin YW, Wang H, Yang YL, Zhang YM, Zhang T (2003) Ten novel mutations in the phenylalanine hydroxylase gene identified in Chinese patients with phenylketonuria. Zhongguo Yi Xue Ke Xue Yuan Xue Bao 25:142-144

Zschocke J (2003) Phenylketonuria mutations in Europe. Hum Mutat 21:345-356 